\title{
Stories as indicators: Lessons learned using the Most Significant Change method to evaluate food systems work in Michigan
}

\author{
Lilly Fink Shapiro, ${ }^{a} *$ Lesli Hoey, ${ }^{\mathrm{b}}$ and Kathryn Colasanti c \\ University of Michigan
}

Submitted May 12, 2020 / Revised September 23 and November 3, 2020 / Accepted November 3, 2020 /

Published online March 19, 2021

Citation: Fink Shapiro, L., Hoey, L., \& Colasanti, K. (2021). Stories as indicators: Lessons learned using the Most Significant Change Method to evaluate food systems work in Michigan. Journal of Agriculture, Food Systems, and Community Development, 10(2), 399-411. https://doi.org/10.5304/jafscd.2021.102.025

Copyright (C) 2021 by the Authors. Published by the Lyson Center for Civic Agriculture and Food Systems. Open access under CC-BY license.

\begin{abstract}
Food systems initiatives regularly use stories as a communication tool to showcase and gain attention for their work. Yet few of these efforts use systematic ways to collect and analyze stories.

Rooted in our experience documenting the work surrounding the Michigan Good Food Charter, we suggest that a variety of efforts that aim to transform food systems could benefit from applying the
\end{abstract}

a * Corresponding author: Lilly Fink Shapiro, Program Manager, Sustainable Food Systems Initiative, School for Environment and Sustainability, University of Michigan; 440 Church Street; Ann Arbor, Michigan 48109-1041 USA; +1-513-368-2311; finkshap@umich.edu

b Lesli Hoey, Associate Professor, Urban and Regional Planning Program, University of Michigan; 2000 Bonisteel Blvd., Art and Architecture Building; Ann Arbor, Michigan 48109 USA; 1hoey@umich.edu

c Kathryn Colasanti, Evaluation Associate, Program Evaluation Group, University of Michigan School of Social Work; 1080 South University Avenue; Ann Arbor, MI 48109 USA; kcolasan@umich.edu
Most Significant Change (MSC) technique, an evaluation tool that uses stories in a more rigorous way to identify emerging outcomes and enhance organizational learning. Particularly with the modifications we introduce, the MSC approach can be adapted to situations where program staff or participants have limited time, resources, or capacity, offering stakeholders a way to build a shared vision of a program and, over time, a clearer sense of the direction that a food systems project has and where it should be headed.

\section{Keywords}

Most Significant Change, Food Systems, Michigan, Evaluation, Equity

\section{Funding Disclosure}

Funding in support of this research was provided by the W. K. Kellogg Foundation

\section{Disclosures}

The main funder supporting this work-the W.K. Kellogg Foundation— did not require the use of a Most Significant Change approach nor were Kellogg Foundation staff involved in conceiving of or writing this article. 


\section{Introduction}

The last decade has seen a precipitous rise of collaborative food systems movements and initiatives across the globe (Filippini, Mazzocchi, \& Corsi, 2019; Glennie \& Alkon, 2018; Hoey, Colasanti, Pirog, \& Fink Shapiro, 2017). Whether food systems initiatives are focused on increasing healthy diets, supporting sustainable agriculture practices, stimulating the local food economy, or promoting greater equity throughout the food system, their complex and rapidly evolving nature makes evaluation difficult. Yet evaluation is imperative for enhancing learning, identifying effective practices, and increasing the impact of initiatives (Levkoe \& Blay-Palmer, 2018). Furthermore, evidence of positive impact can demonstrate to local governments the value of supporting food systems (Clark, Marquis, \& Raja, 2017; Filippini et al., 2019; Roberts, 2014) and convince the philanthropic community to continue to invest in food systems interventions (W. K. Kellogg Foundation, 2020; Global Alliance for the Future of Food, 2020).

One of the challenges of understanding the impact of food systems work is the interconnected nature of factors required to effect change alongside the multiple, interlinked outcomes that can emerge. For example, the goal of increasing food security requires strategic interventions on multiple levels_-from contextually-sensitive household-level programs to national and even global policy change_-as well as actions that are interconnected, linked to environmental sustainability, human health, food access, and livelihood (PinstrupAndersen \& Watson, 2011). From the standpoint of indicators and evaluation, the array of goals, interventions required, and metrics needed to capture and attribute change can quickly become overwhelming (Ericksen et al., 2012).

In these cases, evaluations cannot rely on standard models typically used to assess more straightforward, linear problem-solving efforts. When complex initiatives are assessed using more traditional approaches of evaluation, they are often forced to identify predetermined indicators and prescriptive criteria to monitor, failing to capture unexpected, emerging impacts (Broughton \& Hampshire, 1997). A flexible and adaptive approach is needed that reflects the evolving nature of systems-level change, as the scope of the problem may shift alongside the intervention (Patton, 1994, 2010). Michael Quinn Patton has termed this type of assessment "developmental evaluation," an approach that looks at complex initiatives "in terms of relationships" rather than breaking them down into "discrete components," as traditional evaluation tends to do (Patton, 2016b, p. 8). Rather than monitoring fidelity to a defined set of tasks or testing if an intervention "works" in order to solve a clearly delineated problem, developmental evaluation is useful for interventions where the actors are essentially creating the path as they walk it, learning about the effects of their actions as they go, and regularly adjusting their strategy.

Patton notes that just about any mix of methods can be used to carry out a developmental evaluation, as long as it is flexible and leads to rapid feedback about the effects of ongoing adaptations (Patton, 2016a, p. vi). One method useful in this process of depicting and reflecting on emerging outcomes is the Most Significant Change (MSC) method. The remainder of this paper describes the origin of MSC and how it is typically implemented; why we think that MSC is a good fit for interdisciplinary, collaborative efforts, especially those focused on food systems; how we used, modified, and interpreted findings from MSC in a food systems initiative in Michigan; the limitations of the original model; and the benefits and limitations of the modifications we introduced. Our intention is to expose practitioners and evaluators to a method which we believe will enhance efforts to document, learn from, and continuously improve efforts to transform food systems.

\section{The MSC Method}

The MSC method was developed by Rick Davies in 1996, based on a rural development initiative he was asked to evaluate in Bangladesh. As occurs with many complex change initiatives, he was confronted with a program that was operating in different configurations in more than 700 villages, each with their own unique context. While program managers had a broad goal for the overall program, they were not entirely sure what the actual outcomes would be, leaving Davies with an operation much too complex to summarize with a 
traditional linear, pre-determined evaluation approach. Out of this experience, he developed the MSC method, focused on the collection and collaborative analysis of stories gathered from program participants or field staff (Davies \& Dart, 2005). The aim is to identify emerging outcomes while also offering program staff and other stakeholders a way to build a shared vision of the program and, over time, a clearer sense of the direction that the project has and where it should be headed, or as Jess Dart and Davies put it, to "move towards success and away from failure" (2003, p. 151).

Most evaluators use MSC as a formative evaluation method-to track changes that are emerging during implementation (including unexpected outcomes), to contribute to learning, to identify potential problems, and to help a program make adjustments (Costantino \& Greene, 2003; McClintock, 2004; Willetts \& Crawford, 2007). MSC has also been used for summative evaluation, as a way to identify some of the impacts of a program (Limato, Ahmed, Magdalena, Nasir, \& Kotvojs,
2018; Ramacciotti, 2017). The important caveat that MSC evaluators give-emphasized in our final section-is that the approach is not a stand-alone evaluation method; it is not appropriate for capturing certain types of changes and it must be triangulated with other data to offer a more complete picture of a program's progress and impacts (Davies $\&$ Dart, 2005). It cannot, for instance, be used to determine cost effectiveness, nor could it determine the extent of particular impacts, unless additional methods are used to measure specific indicators across the entire population affected by an initiative. MSC is most useful where: (1) it is not possible to predict in any detail or with any certainty what the outcomes will be, (2) outcomes will vary widely across program participants, (3) there may not yet be agreements between stakeholders on what outcomes are the most important, and (4) the interventions are expected to be highly participatory, including monitoring and evaluating the results (Davies et al., 2005).

As Figure 1 illustrates, the process of analyzing stories, in the original approach developed by

Figure 1. The Typical Process of Collecting and Identifying the "Most Significant" Stories

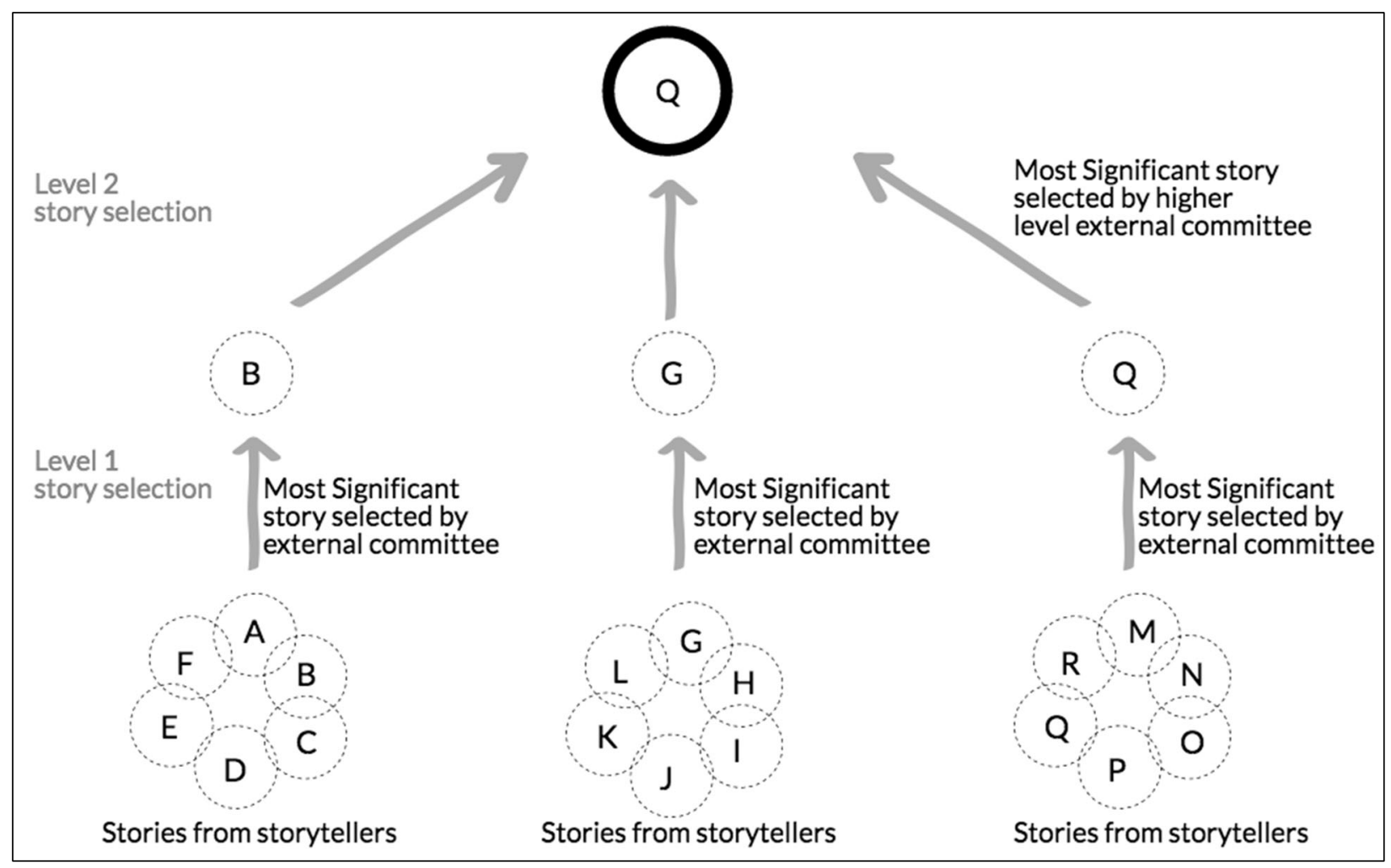

Source: Adapted from Dart and Davies (2003, p. 4). 
Davies and Dart (2005), usually occurs in several rounds, involving dialogue between people involved in all levels of a program.

Typically, a program starts by soliciting a call for "significant stories" from program participants and/or field staff. Stories can be shared in writing, orally through interviews, or in small group discussions. While the definition of "significant" can be open-ended, stories can be requested around certain "domains" of change (e.g., changes in food security) that are relevant to the program, and should have a common timeframe and geographic scope. All stories shared should include an explanation of the change as well as reasons why the storyteller chose to focus on that story, or why it seemed significant to them.

Committees of staff or selected stakeholders at each site across a program then select one story as "most significant" and discuss why they believe that story represents the most significant change out of all the stories they reviewed. These discussions can occur, for example, among a group of storytellers or among a group of field staff reviewing written stories. The dialogue that occurs at this point is critical to the method, as it helps participants hear how others interpreted stories, revealing the values that different actors bring to the table. Such articulation also encourages double-loop learning - a re-examination of an organization's underlying values, assumptions and goals (Argyris \& Schon 1974)—which is critical for the process of helping to reveal adjustments the program may want to make to keep moving actions towards desired change (Davies \& Dart, 2005).

After each site's committee has selected their "most" significant story, they pass the story up to the next level of a program, where another committee of staff and/or stakeholders assemble to discuss and select from a smaller number of "most" significant stories, and so on. The number of rounds of selection can vary based on the scale of the program. Throughout this process:

Every time stories are selected, the criteria used to select them are recorded and fed back to all interested stakeholders, so that each subsequent round of story collection and selection is informed by feedback from previous rounds. The organization is effectively recording and adjusting the direction of its attention - and the criteria it uses for valuing the events it sees there. (Davies \& Dart, 2005, p. 10)

After going through this process once, programs often repeat each of these steps at a later point in time, gathering another round of stories. The frequency with which actors carry out an MSC process varies based on the timeline and scope of a program, as often as every month in the early stages of an intervention or as infrequent as every year or two. After each full round of MSC, evaluators can use the collected stories as a reporting mechanism to illustrate emerging outcomes. The most valuable outcome, however, is often a reflection on the insights that emerged during the dialogue process, which can help stakeholders make programmatic adjustments.

Today, the MSC technique is used to evaluate programs around the world, from health promotion programs in Indonesia (Limato et al., 2018) to ICT (Information Communication Technology) training in Australian schools of education (Heck \& Sweeney, 2013) to food security projects in West Africa (Somda et al., 2017), usually in the form of oral stories documented in writing, but also through participatory video (Asadullah \& Muniz, 2015; Lunch, 2007). MSC appears to be used less often in North America, but there are examples of its application to evaluate asthma programs in Albuquerque public schools (Peterson, 2015), to examine perceptions of sustainability among college students at Penn State (Ramacciotti, 2017), and to assess the challenges at a domestic violence shelter in Canada (Rogers, 2013). With the exception of an evaluation of several refugee farming programs in the US (Gusev, 2015), our team has come across few examples of food systems initiatives in North America using MSC, which we believe is a missed opportunity.

\section{MSC in Food Systems Initiatives}

One reason we argue that MSC is a natural fit for evaluating and improving a variety of food systems initiatives is because so many are already using stories to help communicate their impact and for 
purposes of general reflection. From our experience working in the US context, food systems initiatives are already collecting and featuring stories through their newsletters, websites, and social media platforms, and incorporating storytelling as a central activity during events, meetings, and summits. For example, California-based Roots of Change hosts a podcast about the future of food and farming (Dimock, 2021), the Minnesota Food Charter prominently features stories on their website about "Food Charter Champions" (Minnesota Food Charter, 2020), and Vermont Farm to Plate regularly publishes stories of change, such as "A story of respect and resilience" (Claro, 2018). The Food Dignity Project also has used digital "triplerigorous storytelling" involving "ethical, epistemological and emotional standards of rigor" to document the work of partnering with communitybased organizations through participatory case study research (Porter, 2018, p. 38).

The common use of stories in food systems initiatives is not surprising since stories are powerful tools of influence. Commonly used by politicians and marketers to change people's minds, stories have the potential to convey information in a way that is more memorable and easier to relate to than the same information presented as facts or statistics (McClintock, 2004). For example, a nonprofit may communicate the impact of their work by focusing on how their efforts have changed the life of one family, just as a politician may single out the story of one individual to make a case for a particular policy change. However common it is for stories to be used to influence hearts and minds, these types of individual experiences are anecdotes. Evaluation theorists agree that "the problem with anecdotes is that their 'truth' may not generalize" for the purposes of program decision-making or determining an intervention's broad impact (Royse, Thyer, \& Padgett, 2015, p. 33). While a story may be true for the person who had the experience, to leverage stories effectively as a form of evaluative evidence more rigor is needed in how stories are aggregated and analyzed.

A variety of systematic approaches exist that use storytelling as a tool for qualitative data collection (Polet et al., 2015). Among these narrative forms of evaluation, MSC is more explicitly participatory and value-based, aligning more naturally with the nature and goal of many food systems initiatives. The exploratory and "indicatorfree" nature of the MSC approach (Sigsgaard, 2002) increases the chances of uncovering unintended outcomes. This mirrors the emergent nature of many food systems initiatives, where it may not be possible to come up with predetermined indicators to measure. The MSC participatory data collection and analysis also supports the equity and justice orientation of many food systems initiatives (Burke \& Spiller, 2015). Asking storytellers and case selection committees to articulate "why" they perceive certain stories as most significant centers the evaluation on their values and interpretations, as opposed to those of the evaluators, while the MSC focus on dialogue can move stakeholders to consensus about project aims and strategies in ways that more top-down administered methods may not.

Despite the added value MSC could offer food systems programs, one of the most frequently cited challenges of implementing "full" MSC, as described above, is the significant investment of time required by all stakeholders in the process (INTRAC, 2017; Willetts \& Crawford, 2007). Especially for initiatives working with low-income populations, the time and energy needed to contribute stories and engage in participatory analysis-especially if held over several, ongoing rounds - is heightened when MSC must be combined with other methods that solicit information from the same participants. Furthermore, for under-resourced nonprofit organizations or local governments, time-consuming evaluations like MSC, where staff may be asked to collect stories and participate in the analysis, must be carefully weighed against the time needed to devote to program implementation (Ebrahim, 2005). As a way to expand the opportunity for more people to participate and to lower the burden on program staff, our team considered how we might adapt MSC to our own evaluation of a complex food systems initiative in Michigan, The Michigan Good Food Charter.

\section{MSC in the Michigan Context}

The Michigan Good Food Charter initiative is a 
statewide effort to promote, implement, and track progress toward its goals (Figure 2).

The Charter, launched in 2010 through a multistakeholder dialogue, is centered around the vision of a food system that grows the local food economy, increases equitable food access, and enhances health.

The Good Food Charter Project is structured around a Collective Impact framework (Kania \& Kramer, 2011), and is coordinated by staff at the Center for Regional Food Systems (CRFS) at Michigan State University. Since 2015, our team, based at the University of Michigan, has been working as the external evaluators of the initiative. Because of the diverse stakeholders involved, the wide-ranging goals, the necessity to adapt strategies over time, and the unpredictable nature of the outcomes, we chose to use a developmental evaluation (Patton, 2010) as our overall evaluation framework. The MSC method is one of a mix of other quantitative and qualitative methods we have used to document project activities and to offer CRFS staff ongoing feedback.

As we used MSC on six different occasions, we developed three types of modifications to adapt to different settings, using it with groups of as few as six and as many as sixty. As we describe below, in adapting the original approach to MSC we aimed to glean its core benefits while trying to integrate the method into existing events and program activities seamlessly. With such adaptations, we believe MSC can be used in situations with limited time, money, or capacity. We describe our process in each of these modifications below, as well as how we analyzed the stories we collected.

\section{Analysis of Existing Stories}

The first way that we utilized MSC was to conduct a systematic analysis of 96 existing stories our evaluation partner had already
Figure 3. An Analysis of How Existing Stories Related to Goals of the Michigan Good Food Charter

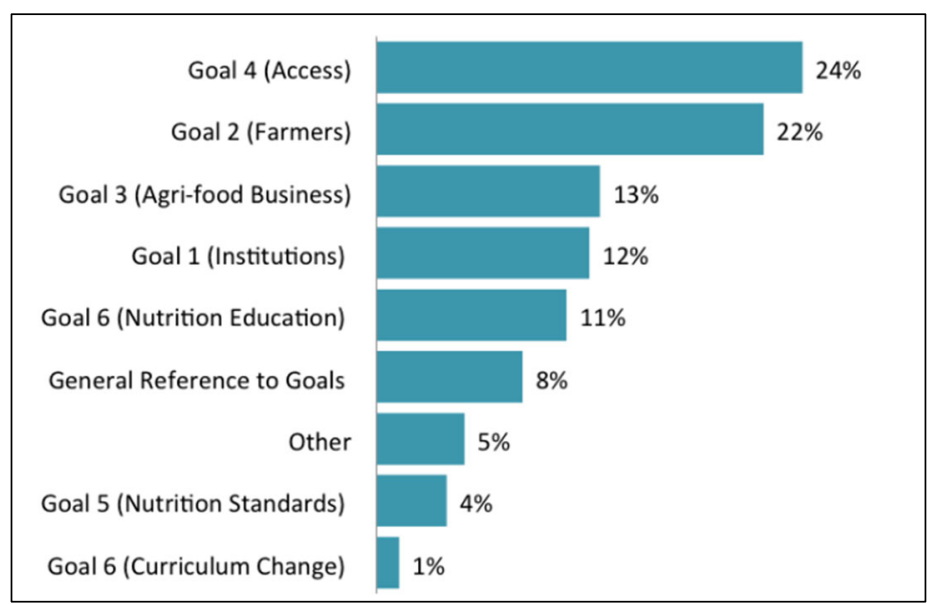


This paved the way for exploring whether this reflected unintentional prioritization on the part of staff or whether this reflected different levels of activity around different goals. Analyzing the location of the stories also allowed us to delineate geographic gaps of regions in the state where they tended to concentrate less (Figure 4).

\section{The MSC Focus Group}

A second simple way in which we adapted MSC was to facilitate a focus group conversation with lead CRFS staff, at the end of the first project year. During the hour-long, six-person focus meeting, our evaluation team asked each person to describe the "most significant change" they had observed over the first year as it related to their work on the Charter. The CRFS team then discussed each of the changes that their colleagues had raised, settling on a single key change that they all agreed best represented the type of change they hoped that their future work on the project would continue to generate. Conducted after the first and second years of

\section{Figure 4. A Spatial Analysis of Good Food Stories in} Michigan (UP=Upper Peninsula)

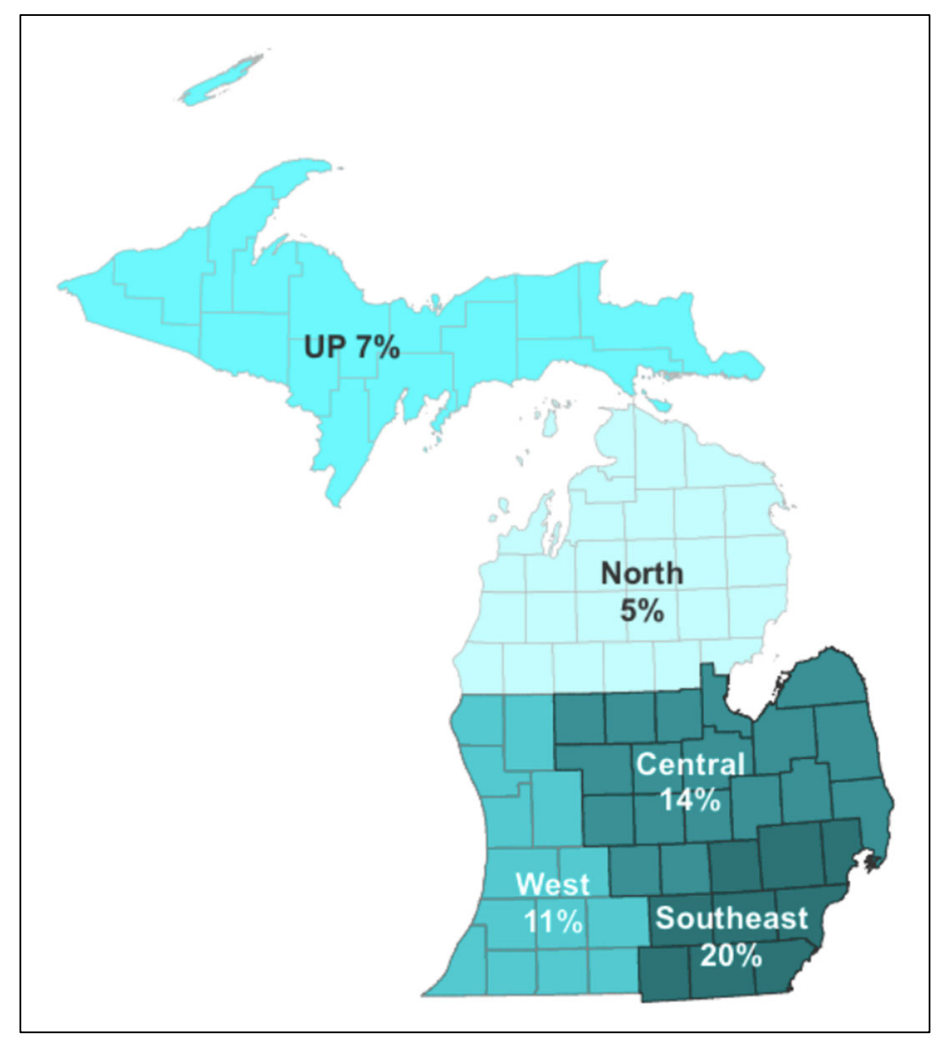

the program, the exercise was intended to help staff build upon early successes and update their project plan, if necessary. As MSC generally does, their conversation helped to make explicit the values that were guiding staff perceptions about the aim of their complex program, increasing the coherence of their collective efforts and clarifying their theory of change. It also allowed us as the evaluation team to identify the key changes that we should emphasize in our first annual evaluation report and the changing priorities that we should begin to observe as the project moved forward. We did not hold MSC sessions with staff-specific groups in subsequent years, opting instead to gather stories from a wider group of stakeholders (see following section), but we could have continued to use it as a regular exercise to provide feedback for each annual report and project planning cycle.

\section{The MSC Storytelling Workshop}

A third and more extensive MSC modification piloted by our team was a "storytelling workshop" we hosted with various groups to integrate a shorter version of the MSC process into existing CRFS meetings, summits, and other gatherings. Our team used this MSC adaptation four times: once with a group of approximately 12 people on the MI Good Food Charter Steering Committee, twice during statewide Good Food Summits as breakout sessions that participants could voluntarily attend, which drew between 40 and 60 people, and once with 15 people as part of a regular statewide network meeting of local food councils.

This latter exercise was particularly instructive. Prior to the MSC session, the local food council network coordinators were hesitant to orient discussions and group activities towards "policy" too directly, for fear of alienating potential network members based on partisan politics. For this same reason, many of the local food councils had chosen to refer to their individual councils as "local food" councils as opposed to "food policy" councils. However, all the stories that the group chose to "lift up" 
during the MSC session were about local policy change which they or their partners had helped enact in their counties or cities, which sent a powerful message to the network conveners about the underlying values of the group and the future direction of the network, which today is more firmly focused on building the capacity of local food councils to carry out policy advocacy.

Like the traditional MSC technique, this third, modified approach to a "storytelling workshop" still retains the core qualities of being participatory, dialogic, and based on perceptions of the most significant changes. One of the biggest differences is that the exercise can be completed within the span of one hour, a typical length for a conference breakout or workshop session which can be easily integrated into regular meetings. There are five steps to this modified MSC approach:

1. The facilitator divides participants into small groups of four to six people. If sufficient evaluation staff (or, in our case, student volunteers) are available, each group is also assigned a facilitator to keep track of time, record the conversation, and manage the process. These roles can also be assigned to group participants.

2. Participants are given a one-page worksheet and asked to reflect individually and write a "5-minute essay" in response to the following question: "Over the last [time period], what do you think was the most significant change in [domain]?" The "domain" category is left deliberately broad, so as not to limit the types of stories the participant reflects upon. In our case, we ask people to reflect on changes they had seen in their community over the last year that reflect the goals of the Michigan Good Food Charter. The worksheet asks participants to write about what happened, why it is important, and the key lesson that emerged from the story that other communities could learn from.

3. After the "5-minute essay," the written stories from each small group are then shared with another small group (table 1 stories go to table 3 , table 2 stories go to table 4, and so forth), ensuring that stories are not passed to the group physically next to the storytellers, as it can be distracting for participants to hear their story being discussed by a neighboring group.

4. Each group member reads one story aloud to their group. As in the traditional MSC approach, the group then discusses the qualities of each story and comes to an agreement on which of the stories represents the "most significant change" and why. The dialogue that takes place in each small group is central to the richness of the method. In our experience, it is helpful for a moderator to encourage every group member to speak and to draw out "why" a particular change is significant to each person.

5. After the small group discussions, the workshop facilitator then calls upon one representative from each group to share with the large group the single story they have chosen to "lift up" as most significant and explain why their group selected that story.

When we used this approach in the statewide Good Food Summits, we collected 40 to 60 stories each time. We analyzed the stories based on the goals of the Michigan Good Food Charter, tracked other unexpected changes that were unrelated to the Charter goals, and mapped the locations of the stories geographically, since Michigan Good Food Summits draw participants from across the state. Because we were interested in the scope of Charter and other food systems-related changes that were observed, we also coded stories based on a "results ladder" (Figure 5), as described by Kibel (1999). This involved categorizing stories based on whether participants were (1) observing successful efforts to gather the inputs necessary to start an initiative (e.g., submitting a grant, securing funding or staff); (2) describing activities or implementation processes (e.g., trainings or meetings held); 
(3) observing short-term outcomes

(e.g., greater awareness or skills acquired); and/or (4) observing long-term impacts (e.g., on health or jobs).

This analysis reflected back to CRFS that participants were most observant of Michigan Good Food Charter work that focused on carrying out activities that emphasized the process of taking action or achieving some initial short-term outcomes. The MSC analysis revealed that the longer-term economic, health, and environmental impact of the Charter was not yet apparent to many participants. In part, this finding indicates that longterm project impacts take time and may not have materialized yet. Additionally, activities with which people are involved and short-term outcomes are easier to observe and recall. This is similar to the tendency of organizations to measure outputs-number of meetings held, how many people participated, etc.-because they are easier to measure than the impacts of those meetings (Whitworth \& Wells, 2007). Alternatively, in Davies and Dart's (2005) experience, participants tend to value stories of impact most highly, suggesting that if more longterm impact stories were salient, participants might have focused on these. Ultimately, what we found does not necessarily mean that the goals of the Michigan Good Food Charter were not being met, but suggest further exploration is needed using other methods to consider the extent to which progress is being made toward longer-term impacts.

\section{Limitations and Further Adaptations}

There are several critiques of the traditional MSC approach, most of which also apply to our own modified approaches. First, the method can be biased towards those who are particularly good at telling (or writing) stories, especially because of issues with language or literacy (INTRAC, 2017). Additionally, as a result of the shortened length of the storytelling process in our modifications, some stories may lose meaningful detail. Davies and Dart (2005) warn that this can happen with shorter stories, but also explain that the desirable length of stories varies depending on the needs and culture of the organization, so that even short, to-the-point stories can be useful as long as they offer enough detail to be validated and to allow for meaningful deliberation. One suggestion to avoid the potential bias towards strong writers or natural storytellers and to counteract the loss of depth in shorter stories is for staff members to interview people who have stories to tell and to follow-up with storytellers who produced a shortened version in order to elicit more detail and depth. Gathering more information also helps as a form of validation, a particularly useful practice with stories that rise to the top as "most significant" (INTRAC, 2017).

A second criticism of MSC is that, depending on the design, the approach tends to elicit positive stories of change (INTRAC, 2017). The first time we used the workshop approach in a statewide food summit, we also found that the "why" explanation offered by individuals and groups tended to lift up positive stories. Stories that had multiple positive benefits were especially valued, such as those with simultaneous impacts on farmer livelihoods and food access in low-income communities. Initiatives that had broader, usually statewide, impact were also selected over stories of change that took place on a local level. While evaluators should be aware of this potential positive bias, a focus on stories of successful change may still be appropriate if a project is using an "asset-based" model focused on identifying and building upon a community's existing capacity and 
assets (Kretzmann \& McKnight, 1996).

Alternatively, one change we began to implement, which Dart and Davies suggested (2003), is to intentionally ask storytellers to share either (or both) positive or negative stories or stories of "lessons learned" in order to elicit a more wellrounded picture of change. In a similar vein, the story collection process could focus more intentionally on seeking out stories from known critics of the program (Willetts \& Crawford, 2007; Dart \& Davies, 2003).

A third point to remember about MSC, as was noted earlier, is that the developers of the approach never intended for it to be used in isolation from other methods or as a systematic way to determine wider trends (Davies \& Dart, 2005). In the Michigan context, our evaluation team has used MSC alongside surveys, interviews, participant observation, document review and other methods. Triangulating the MSC with other approaches like this is an additional way to ensure that an evaluation is capturing unintended - perhaps negative-impacts and problems which are emerging in a project. Any unexpected changes and outcomes MSC uncovers can also become the basis for a survey, or a more systematic assessment, to determine if particular MSC stories were representative of larger trends, or solely occurring in a singular case.

Finally, another lesson we have learned in using MSC is the importance of maintaining respect for storytellers. This is a consideration in the MSC literature that has not, to our knowledge, received adequate attention. As a participant in one of our MSC sessions put it, "I think it's important to respect people's space in storytelling and also be aware that sharing invokes/requires vulnerability. Additionally, many people/cultures have been violated/bastardized/pimped by those 'harvesting' [stories]." As this participant was conveying, facilitators should be sensitive to the potential emotional toll of telling stories and to the desire of storytellers to own their stories. This concern is also a reminder that effectively using MSC and ensuring the integrity of stories requires building trusting and respectful relationships between those telling and gathering stories, as well as transparency about the collection and use of stories (Willetts \& Crawford, 2007). Whether and how to use stories, and how to elicit them from whom, should be a collective decision of all stakeholders involved. In our case, one modification we made to increase people's comfort in our "storytelling workshops" was to ask participants to indicate on their essay if they wanted to remain anonymous. Passing stories to others in a large group, rather than having individuals read their own stories, also increases comfort in anonymity.

\section{Conclusion}

From Vermont to Minnesota to Michigan, there is substantial evidence that multistakeholder food systems initiatives are already using stories in a variety of strategic ways (Fink Shapiro et al., 2015). Rooted in our experience evaluating the work surrounding the Michigan Good Food Charter, we suggest that the MSC technique offers a way to collect and analyze stories in a more systematic way, turning storytelling into an effective evaluation tool.

In our own experience, our evaluation clients have shared how participating in the MSC sessions has given them perspective and clarity about their work. Other participants have expressed appreciation for hearing about the variety of food systems changes other stakeholders perceive, while learning a new technique they may use in their own work. One participant described MSC as a "great and a new way to look at gathering and measuring data within a community." The MSC has helped focus our attention, as evaluators, on the types of changes Charter stakeholders value most. At the same time, we continue to pay attention to triangulated methods, which help to elucidate long-term impacts or other challenges that are not otherwise apparent in MSC data.

Under ideal conditions, community-based organizations and individuals striving to transform food systems would have the funding and time to develop detailed stories about their work, using strategies like "triple-rigorous storytelling" (Porter, 2018, p. 38). Implementing the full version of the traditional MSC approach as intended by Davies and Dart (2005) is thus ideal, as it allows for a richness of discovery and ongoing discussion among diverse stakeholders engaging in collective change making - a level of deliberation that may 
not be attainable with the modified versions we have implemented. However, considering time, capacity, and resource constraints, we believe that our adaptations are valuable, offering a systematic way to collect and analyze the stories that many food systems initiatives are already using.

\section{References}

Argyris, C., \& Schon, D. (1974). Theory in practice: Increasing professional effectiveness. San Francisco, CA: Jossey-Bass.

Asadullah, S., \& Muniz, S. (2015). Participatory video and the most significant change. Oxford, UK: InsightShare. https://insightshare.org/resources/participatory-video-and-the-most-significant-change/

Broughton, B., \& Hampshire, J. (1997). Bridging the gap: A guide to monitoring and evaluating development projects. Canberra, AU: Australian Council for Overseas Aid.

Burke, J. D., \& Spiller, K. A. (2015). Food Solutions New England: Racial equity, food justice, and food system transformation. Journal of Agriculture, Food Systems, and Community Development, 5(4), 165-171. https://doi.org/10.5304/jafscd.2015.054.027

Clark, J. K., Marquis, C., \& Raja, S. (2017). The local food policy audit: Spanning the civic-political agrifood divide. In I. Knezevic, A. Blay-Palmer, C. Z. Levkoe, P. Mount, \& E. Nelson (Eds.), Nourishing communities: From fractured food systems to transformative pathways (pp. 131-146). Cham, Switzerland: Springer. https://link.springer.com/chapter/10.1007/978-3-319-57000-6 8

Claro, J. (2018, September 26). A story of respect and resilience. Montpelier, VT: Vermont Sustainable Jobs Fund, Face of Farming Series. https://www.vsjf.org/2018/09/26/a-story-of-respect-and-resilience/

Costantino, T. E., \& Greene, J. C. (2003). Reflections on the use of narrative in evaluation. American Journal of Evaluation, 24(1), 35-49. https://doi.org/10.1177/109821400302400104

Dart, J., \& Davies, R. (2003). A dialogical, story-based evaluation tool: The Most Significant Change technique. American Journal of Evaluation, 24(2), 137-155. https://doi.org/10.1177/109821400302400202

Davies, R., \& Dart, J. (2005). The 'Most Significant Change' (MSC) technique: A guide to its use. https://www.mande.co.uk/wp-content/uploads/2005/MSCGuide.pdf

Dimock, M. R. (Host). (2021). Flipping the table [podcast]. Oakland, CA: Roots of Change, Public Health Institute. https://www.rootsofchange.org/flippingthetablepodcast/

Ebrahim, A. (2005). Accountability myopia: Losing sight of organizational learning. Nonprofit and Voluntary Sector Quarterly, 34(1), 56-87. https://doi.org/10.1177/0899764004269430

Ericksen, P., Stewart, B., Dixon, J., Barling, D., Loring, P., Anderson, M., \& Ingram, J. (2010). The value of a food system approach. In J. Ingram, P. Ericksen, \& D. Liverman (Eds.), Food security and global environmental change (pp. 25-45), Oxon, UK: Earthscan/Routledge.

Filippini, R., Mazzocchi, C., \& Corsi, S. (2019). The contribution of Urban Food Policies toward food security in developing and developed countries: A network analysis approach. Sustainable Cities and Society, 47, 101506. https://doi.org/10.1016/j.scs.2019.101506

Fink Shapiro, L., Hoey, L., Colasanti, K., \& Savas, S. A. (2015). You can't rush the process: Collective impact models of food systems change. East Lansing: Michigan State University Center for Regional Food Systems. https://www.canr.msu.edu/resources/collective impact models of food systems change

Glennie, C., \& Alkon, A. H. (2018). Food justice: Cultivating the field. Environmental Research Letters, 13(7), 073003. https://doi.org/10.1088/1748-9326/aac4b2

Global Alliance for the Future of Food. (2020). Systemic solutions for healthy food systems: A guide to government action. https://futureoffood.org/

Gusev, E. (2015, October 8). Most Significant Change (MSC) [Conference presentation]. The National Incubator Farm Training Initiative 2015 Conference, Chapel Hill, NC. https://nesfp.org/sites/default/files/resources/msc technique nifti 2015.pdf

Heck, D., \& Sweeney, T. (2013). Using Most Significant Change stories to document the impact of the teaching teachers for the future project: An Australian teacher education story. Australian Educational Computing, 27(3), 36-47. https://acce.edu.au/sites/acce.edu.au/files/pj/journal/AEC27-3 HeckSweeney.pdf 
Hoey, L., Colasanti, K., Pirog, R., \& Fink Shapiro, L. (2017). Implementing collective impact for food systems change: Reflections and adaptations from Michigan. Journal of Agriculture, Food Systems, and Community Development, 7(2), 101-115. https://doi.org/10.5304/jafscd.2017.072.014

INTRAC. (2017). Most Significant Change: INTRAC for Civil Society [Factsheet]. Retrieved from https://www.intrac.org/wpcms/wp-content/uploads/2017/01/Most-significant-change.pdf

Kania, J., \& Kramer, M. (2011). Collective impact. Stanford Social Innovation Review, 9(1), 36-41.

Kibel, B. M. (1999). Success stories as hard data: An introduction to results mapping. Boston, MA: Springer.

Kretzmann, J., \& McKnight, J. P. (1996). Assets-based community development. National Civic Review, 85(4), $23-29$. https://doi.org/10.1002/ncr.4100850405

Levkoe, C. Z., \& Blay-Palmer, A. (2018). Food Counts: Food systems report cards, food sovereignty and the politics of indicators. Canadian Food Studies/La Revue canadienne des études sur l'alimentation, 5(3), 49-75. https://canadianfoodstudies.uwaterloo.ca/index.php/cfs/article/view/277

Limato, R., Ahmed, R., Magdalena, A., Nasir, S., \& Kotvojs, F. (2018). Use of most significant change (MSC) technique to evaluate health promotion training of maternal community health workers in Cianjur district, Indonesia. Evaluation and Program Planning, 66, 102-110. https://doi.org/10.1016/j.evalprogplan.2017.10.011

Lunch, C. (2007). The Most Significant Change: Using participatory video for monitoring and evaluation. Participatory Learning and Action, 56(Sec. 4), 28-32. Retrieved from https://pubs.iied.org/G02906

McClintock, C. (2004). Using narrative methods to link program evaluation and organization development. The Evaluation Exchange, 9(4), 14-15. http://www.education.sa.gov.au/sites/default/files/using narrative methods to link program evaluation and o rganization_development.pdf?v=1456977988

Minnesota Food Charter. (2020). Minnesota Food Charter for our bealthy future. https://www.mnfoodcharter.com

Patton, M. Q. (1994). Developmental evaluation. Evaluation Practice, 15(3), 311-319. https://doi.org/10.1016/0886-1633(94)90026-4

Patton, M. Q. (2010). Developmental evaluation: Applying complexity concepts to enhance innovation and use. New York: Guilford.

Patton, M. Q. (2016a). Preface. In M. Q. Patton, K. McKegg, \& N. Weihipeihana (Eds.), Developmental evaluation exemplars: Principles in practice (pp. v-x). New York \& London: Guilford.

Patton, M. Q. (2016b). State of the art and practice of developmental evaluation: Answers to common and recurring questions. In M. Q. Patton, K. McKegg, \& N. Weihipeihana (Eds.), Developmental evaluation exemplars: Principles in practice (pp. 1-24). New York \& London: Guilford.

Peterson, A. B. (2005). APS Asthma Program Evaluation 2005-2006. Albuquerque, NM: Albuquerque Public Schools; Research, Development and Accontability. https://www.aps.edu/sapr/documents/2005-2006-publications/Asthma Program Eval.pdf

Pinstrup-Andersen, P., \& Watson II, D. D. (2011). Food policy for developing countries: The role of government in global, national, and local food systems. Ithaca, NY: Cornell University Press.

Polet, F., Malaise, G., Mahieu, A., Utrera, E., Montes, J., Tablang, R., ... \& De Vos, P. (2015). Empowerment for the right to health: The use of the "Most Significant Change" methodology in monitoring. Health and Human Rights, 17(2), 71-82. https://pubmed.ncbi.nlm.nih.gov/26766863/

Porter, C. M. (2018). Triple-rigorous storytelling: A PI's reflections on devising case study methods with five community-based food justice organizations. Journal of Agriculture, Food Systems, and Community Development, 8(A), 37-61. https://doi.org/10.5304/jafscd.2018.08A.008

Ramacciotti, F. A. (2017). What makes Penn State students go green? Examining 'most significant change' experiences in individuals' sustainability perceptions (Unpublished honors thesis). University Park: Pennsylvania State University. https://honors.libraries.psu.edu/catalog/4467far5069

Roberts, W. (2014). Food for city building: A field guide for planners, actionists \& entrepreneurs. Toronto, ON: Hypenotic.

Rogers, E. (2013). The Most Significant Change 2012-2013. Calgary, AB: Discovery House. https://policywise.com/wpcontent/uploads/2016/07/Housing-and-Homelessness-Most-Significant-Change-Project-Discovery-House.pdf 
Royse, D., Thyer, B. A., \& Padgett, D. K. (2015). Program evaluation: An introduction to an evidence-based approach. Boston, MA: Cengage Learning.

Sigsgaard, P. (2002). Monitoring without indicators: An ongoing testing of the MSC approach. Evaluation Journal of Australasia, 2(1), 8-15. https://doi.org/10.1177/1035719X0200200104

Somda, J., Zougmoré, R., Sawadogo, I., Bationo, B. A., Buah, S., \& Abasse, T. (2017). Adaptation processes in agriculture and food security: Insights from evaluating behavioral changes in West Africa. In J. I. Uitto, J. Puri, \& R. D. van den Berg (Ed.), Evaluating climate change action for sustainable development (pp. 255-269). Cham, Switzerland: Springer. https://doi.org/10.1007/978-3-319-43702-6 14

Whitworth, J. A., \& Wells, R. (2007). Assessing outcomes of health and medical research: Do we measure what counts or count what we can measure? Australia and New Zealand Health Policy, 4, Art. 14. https://doi.org/10.1186/1743-8462-4-14

Willetts, J., \& Crawford, P. (2007). The most significant lessons about the Most Significant Change technique. Development in Practice, 17(3), 367-379. https://doi.org/10.1080/09614520701336907

W. K. Kellogg Foundation. (2020). A community food revolution is underway. East Battle Creek, MI: W. K. Kellogg Foundation. http://communityfood.wkkf.org/ 